\title{
Atlantoaxial Instability Treated with Posterior Atlantoaxial Fixation in Two Siblings with Dyggve-Melchior-Clausen Syndrome
}

\author{
Abhidha SHAH, Sagar BHAMBERE, Shashi RANJAN, Saswat DANDPAT, Atul GOEL \\ Seth G.S. Medical College and K.E.M Hospital, Department of Neurosurgery, Mumbai, India \\ Corresponding author: Atul GOEL atulgoel62@hotmail.com
}

\section{ABSTRACT}

AIM: To discuss the rare association of atlantoaxial instability in patients with the Dyggve-Melchior-Clausen syndrome, a rare autosomal recessive disease characterized by progressive spondyloepimetaphyseal dysplasia and mild to severe mental retardation.

MATERIAL and METHODS: We report an uncommon association of two siblings with Dyggve-Melchior-Clausen syndrome, odontoid hypoplasia and atlantoaxial instability. Both the patients were treated with Goel's atlantoaxial fixation procedure.

RESULTS: The patients had a remarkable neurological recovery following the stabilization procedure.

CONCLUSION: Atlantoaxial instability is a potentially life-threatening condition in patients with this syndrome and should be treated early with atlantoaxial stabilization. Recognition and treatment of atlantoaxial instability in patients with Dyggve-MelchiorClausen syndrome can give gratifying results.

KEYWORDS: Dyggve-Melchior-Clausen syndrome, Atlantoaxial instability, Odontoid hypoplasia, Atlantoaxial fixation

\section{INTRODUCTION}

$\mathrm{D}$

yggve- Melchior- Clausen syndrome (DMC syndrome) is a rare autosomal recessive disease with less than 70 cases reported in world literature. Only 3 cases have been reported in the Indian subcontinent $(4,10)$. The syndrome is more commonly seen in Lebanon, Greenland, Egypt and Morocco $(1,11,12)$. The hallmarks of the syndrome are progressive spondyloepimetaphyseal dysplasia and mild to severe mental retardation. The syndrome is often misdiagnosed as Morquoi's syndrome due to resemblance of its clinical presentation. The absence of corneal clouding, mental retardation, deafness and cardiac abnormalities differentiate Morquoi's syndrome from DMC syndrome $(1,4,10-12)$. The characteristic clinical manifestation of DMC syndrome include short - trunk dwarfism, coarse facies, barrel shaped thorax, microcephaly and rhizomelic limb shortening.
Skeletal abnormalities of the pelvis, hip and spinal column are common findings. Odontoid hypoplasia and atlantoaxial instability have been infrequently reported as components of the DMC syndrome $(4,11,12)$. We report the rare association of odontoid hypoplasia and atlantoaxial instability in two siblings with DMC syndrome.

\section{CASES}

Special informed consent was obtained from the legal guardian of the patients for whom identifying information is included in this article.

\section{Case 1:}

A 16-year-old female born of a second degree consanguineous marriage started having failure to thrive, delayed motor milestones and recurrent respiratory tract infections since
Abhidha SHAH (10): 0000-0002-2784-4401

Sagar BHAMBERE (10): 0000-0002-3374-9910

Shashi RANJAN (D): 0000-0001-9718-7411
Saswat DANDPAT (D) : 0000-0001-7756-454X

Atul GOEL (1) : 0000-0001-5224-6414 
she was 10 months of age. She had been diagnosed as a case of DMC syndrome along with her brother. The other three children in the family were normal. For the last 5 years she had increasing difficulty in walking with inability to stand. The weakness progressed to involve all the 4 limbs and she ultimately became bed-ridden and completely dependent on her parents for survival. When presented for treatment, she had spastic quadriparesis with power of $1 / 5$ in all 4 limbs. She also had breathing difficulty and used accessory muscles for breathing. On general examination she had a short neck and dwarfism. Her height and weight were below the third percentile for her age. She had a pigeon shaped chest deformity, with widening of the wrists and ankles. There was restricted extension at the elbows and the knees. The abdominal wall was hypotonic and the abdomen was protuberant. She had no organomegaly and her ophthalmological evaluation was normal. She had delayed speech, language and motor milestones with severe mental retardation. Her predominant mode of communication was non-verbal accompanied by incoherent vocalization. Her biochemical investigations were essentially normal. Her urinary glycosaminoglycans were mildly elevated but two - dimensional electrophoretic separation of the glycosaminoglycans revealed a normal pattern. Skeletal survey showed features of epiphyseal and metaphyseal dysplasia. Radiologic examinations of the upper and lower limbs showed short bones with underdeveloped epiphyseal and metaphyseal ends and phalanges. There was presence of coxa vera with genu valgum. The acetabula and femoral capital epiphysis were hypoplastic and the femoral necks were wide. The iliac bones showed the typical abnormality of DMC syndrome with small ilia and lace like borders with thickened iliac crest (Lacy iliac crests). The scapulae were squared and the glenoid cavity was hypoplastic. X-ray of the lumbar spine showed characteristic double hump shaped vertebral end plates with platyspondyly and central beaking. The anterior vertebral ends were bulbous in the thoracic spine. MRI of the craniovertebral junction showed odontoid hypoplasia with peri-odontoid ligamentous hypertrophy. CT scan of the craniovertebral junction showed odontoid hypoplasia with Type 1 atlantoaxial facetal instability (6). (Figure 1A-F) The anterior arch of atlas was bifid. The vertebral arteries on both the sides were high riding.

Atlantoaxial stabilization was done using the techniques described by us earlier and is summarized here $(7,8)$. The patient was placed in a prone position after application of Gardner Wells traction tong. Visual inspection and manual manipulation of bones showed a highly mobile and unstable atlantoaxial joint. The atlantoaxial joints were exposed widely on both sides widely amidst venous bleeding. The articular cartilage was widely denuded and bone graft was stuffed into the articular cavity. A standard C1 lateral mass and C2 pedicle

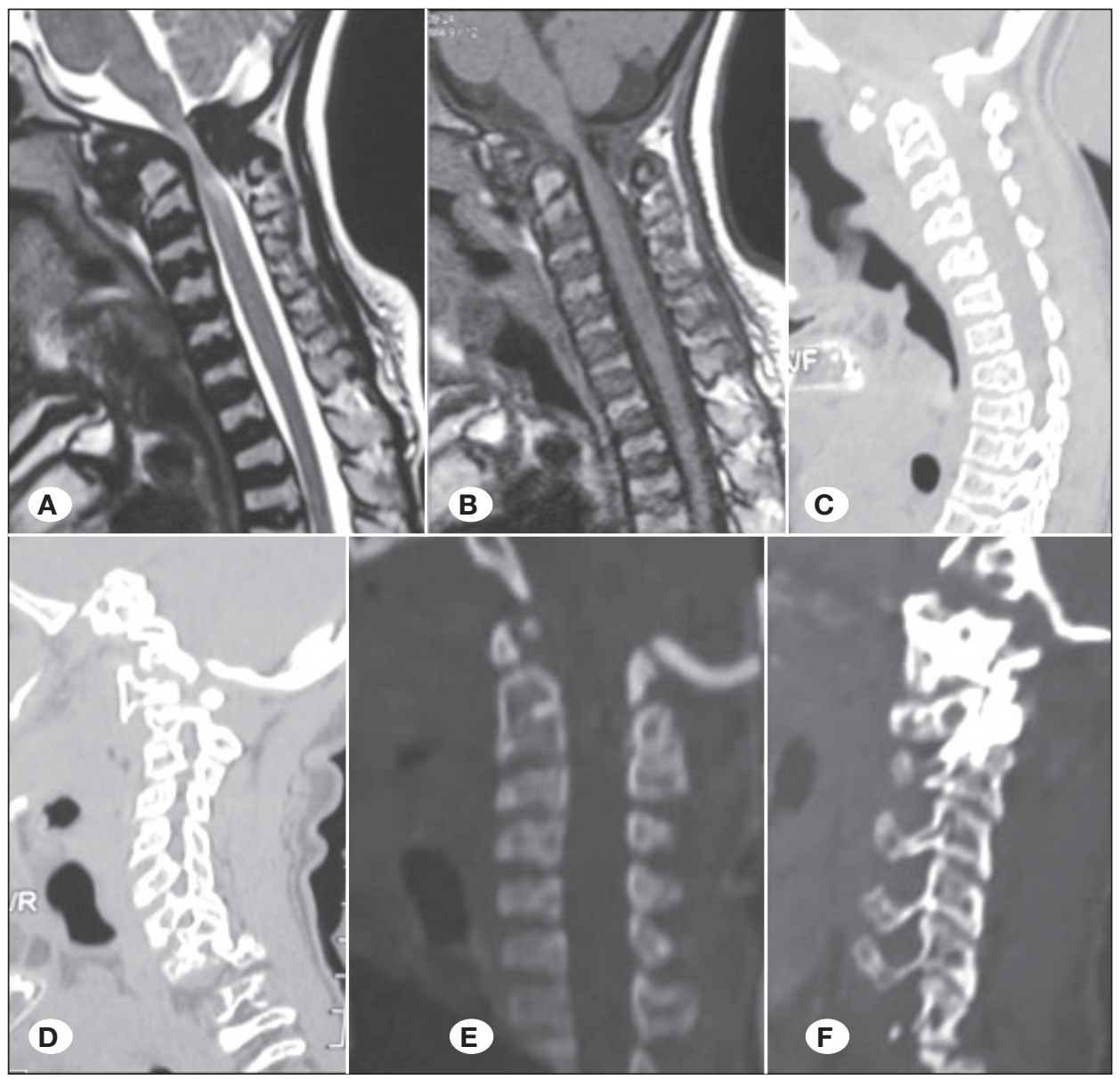

Figure 1: Images of a 16-year female patient;

A) T2 weighted MRI image showing cord compression, odontoid hypoplasia and atlantoaxial instability. B) T1 weighted MRI showing the odontoid hypoplasia, peri-odontoid ligamentous hypertrophy and atlantoaxial instability.

C) Sagittal CT cut showing the odontoid hypoplasia and atlantoaxial instability.

D) Sagittal cut of CT through the facets showing Type 1 atlantoaxial instability.

E) Post-operative sagittal CT scan showing the craniovertebral realignment.

F) Post-operative sagittal CT cut through the facets showing the implant. The C2 screw is in a reverse caudal direction into the $\mathrm{C} 2$ inferior facet of C2. 
screw fixation was performed on one side and on the other side a C1 lateral mass and C2 inferior facet screw fixation was performed (5). In lieu of the high riding vertebral arteries, mobilization of the vertebral arteries was done as has been discussed by us recently prior to $\mathrm{C} 2$ pedicle screw insertion on one side and on the other side a caudally directed C2 screw was inserted into the inferior facet of $\mathrm{C} 2$ as has been reported by us earlier $(5,9)$. The screw purchase was satisfactory. The muscles attached to the C2 spinous process were cut and the host bone of posterior elements of atlas and axis was decorticated to make it a suitable recipient for the bone graft. The patient improved in her stiffness and weakness in the immediate post-operative period. Her breathing became better and she was more comfortable. Post-operative imaging showed satisfactory stabilization of the craniovertebral junction (Figure 1A-F). At follow up of 17 months the patient is doing well, she is able to stand on her own and walk with support.

\section{Case 2:}

A 14-year-old male child, brother of the first patient was born a full term normal delivery but had poor growth since childhood. His motor milestones were normal. He was found to have hyperactivity with inability to sit at one place and poor concentration. On joining school he was found to have academic difficulty and was diagnosed to have mild mental retardation. He had started having difficulty in running with frequent falls for the last one year. He was brought to the hospital for evaluation with his sister. On neurological examination he was found to have spasticity in all 4 limbs with exaggerated reflexes. There was mild weakness in all 4 limbs and he was able to carry out his daily activities with mild difficulty. On general examination he was found to have the characteristic features of DMC syndrome. His height and weight were below the third percentile for his age. He had a pigeon shaped deformity, with hypertelorism and coarse facies. There was restricted extension at the elbows and the knees. The abdomen wall was protuberant. There was no organomegaly and the ophthalmological evaluation was normal. Cardiac evaluation and 2D echo were normal. Skeletal survey showed features of epiphyseal and metaphyseal dysplasia. Radiologic examinations of the upper and lower limbs showed short tubular bones with underdeveloped epiphyseal and metaphyseal ends and phalanges. There was presence of genu valgum. The iliac bones showed the typical abnormality of DMC syndrome with lace like borders and thickened iliac crest (Lacy iliac crests). X-ray of the spine showed characteristic double hump shaped vertebral end plates with platyspondyly and central beaking. The patient had all the characteristic features of the syndrome but seemed to have a milder expression than that of his sister. MRI of the craniovertebral junction showed odontoid hypoplasia with periodontoid ligamentous hypertrophy. CT of the craniovertebral junction showed odontoid hypoplasia with Type 1 atlantoaxial facetal instability (Figure 2A-D). The vertebral arteries on both the sides were high riding. The patient was operated one month after his sister's surgery and the steps of the surgery have been elaborated above. Standard C1 lateral mass and C2 pedicle screw fixation was performed $(7,8)$. The patient did well following surgery and improved in his spasticity and weakness. Post-operative imaging showed good fixation of the craniovertebral junction. At follow up of 16 months the child is back to his normal life and has no neurological deficits.

\section{DISCUSSION}

Dyggve - Melchior - Clausen syndrome (DMC syndrome) was first described by H. V. Dyggve, JC Melchior and J. Glausen as a new form of dwarfism associated with mild to severe mental retardation (3). It a rare autosomal recessive disorder, which results from mutations in the dymeclin (DYM) gene in the 18q12-12.1 chromosomal region $(1,4,10-$ 12). The characteristic clinical findings of the syndrome include progressive spondyloepimetaphyseal dysplasia,
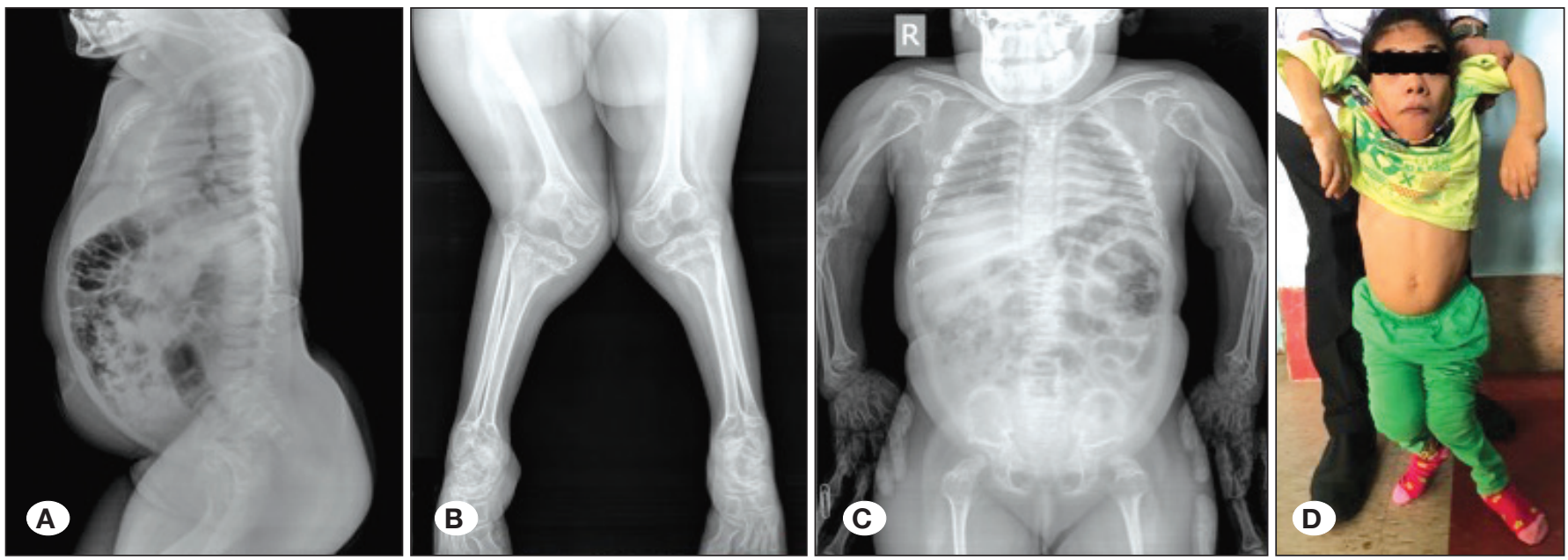

Figure 2: X-ray and clinical photograph of the 16 year old female patient. A) Lateral radiograph of the patient showing the typical double hump appearance of the vertebrae with central beaking and the protuberant abdomen. B) Antero-posterior radiograph showing the knees with genu valgum. C) Antero-posterior radiograph of the chest and abdomen showing the lacy iliac crests and the hypoplastic femoral capital epiphysis. D) Clinical photograph of the patient. 
microcephaly, mental retardation and coarse facies $(1,4,10,12)$. DMC syndrome is often confused with Smith - McCort dysplasia and Morquio's disease (1,2,4,10-12). Smith - McCort dysplasia has very similar clinical features as the DMC syndrome but can be differentiated from it by the absence of mental retardation in the former (2). The lack of corneal clouding, deafness, joint hyperextensibility, cardiac valvular abnormalities, mucopolysaccharidosis and the presence of mental retardation differentiates DMC syndrome from Morquio's disease $(1,4,10-12)$. The pathogenesis of DMC syndrome is not very clear. The syndrome is believed to be due to a deficiency of a specific sulfatase and/or protease causing a problem in degradation of proteoglycans, an error in glycoprotein - adenosine monophosphate metabolism or an endoplasmic storage disorder resulting in a defect in enchondral ossification (10-12). The clinical manifestations of the disease are usually recognized between 1 to 18 months of age. The radiologic abnormalities usually seen include microcephaly, platyspondyly with central depression of end plates resembling a double hump shape, broad ribs, lace like iliac crests, irregular acetabular cavities, wide symphysis pubis, a narrow small pelvis and medially rotated femoral heads. The characteristic radiologic features of double hump vertebrae and lacy iliac crests are usually apparent by 3-4 years of age and persist into adult life and help in clinching the diagnosis $(1,4,10-12)$.

Odontoid hypoplasia and atlantoaxial instability have been reported in patients with DMC syndrome but more frequently have been reported as being asymptomatic $(1,4,11,12)$.
Odontoid hypoplasia has been described in 12 patients with DMC syndrome. Six patients had no neurological symptoms. Out of the 6 symptomatic patients, one patient underwent occipito-cervical stabilization. One patient was treated with anterior transarticular fixation due to the irregular course of the vertebral artery (11). The treatment details of the other symptomatic patients were not clearly available in the literature.

Our patients were born of a second-degree consanguineous marriage to normal parents. They had three normal siblings. This confirms the autosomal recessive nature of the syndrome. Both the patients had varying degrees of mental retardation and other classical clinical and radiologic features of DMC syndrome. We treated both the patients with a posterior $\mathrm{C} 1$ lateral mass and $\mathrm{C} 2$ pedicle screw fixation. Both the patients had high riding vertebral arteries, which were mobilized prior to screw fixation as has been reported by us recently (9). The prognosis of patients with DMC syndrome is not as dismal (Figure $3 A-F)$. Atlantoaxial instability is a potentially lifethreatening condition in these patients and should be treated early with atlantoaxial stabilization.

\section{CONCLUSION}

Atlantoaxial instability is a potentially devastating condition associated with patients of DMC syndrome. Prompt recognition and atlantoaxial stabilization offers gratifying clinical results.

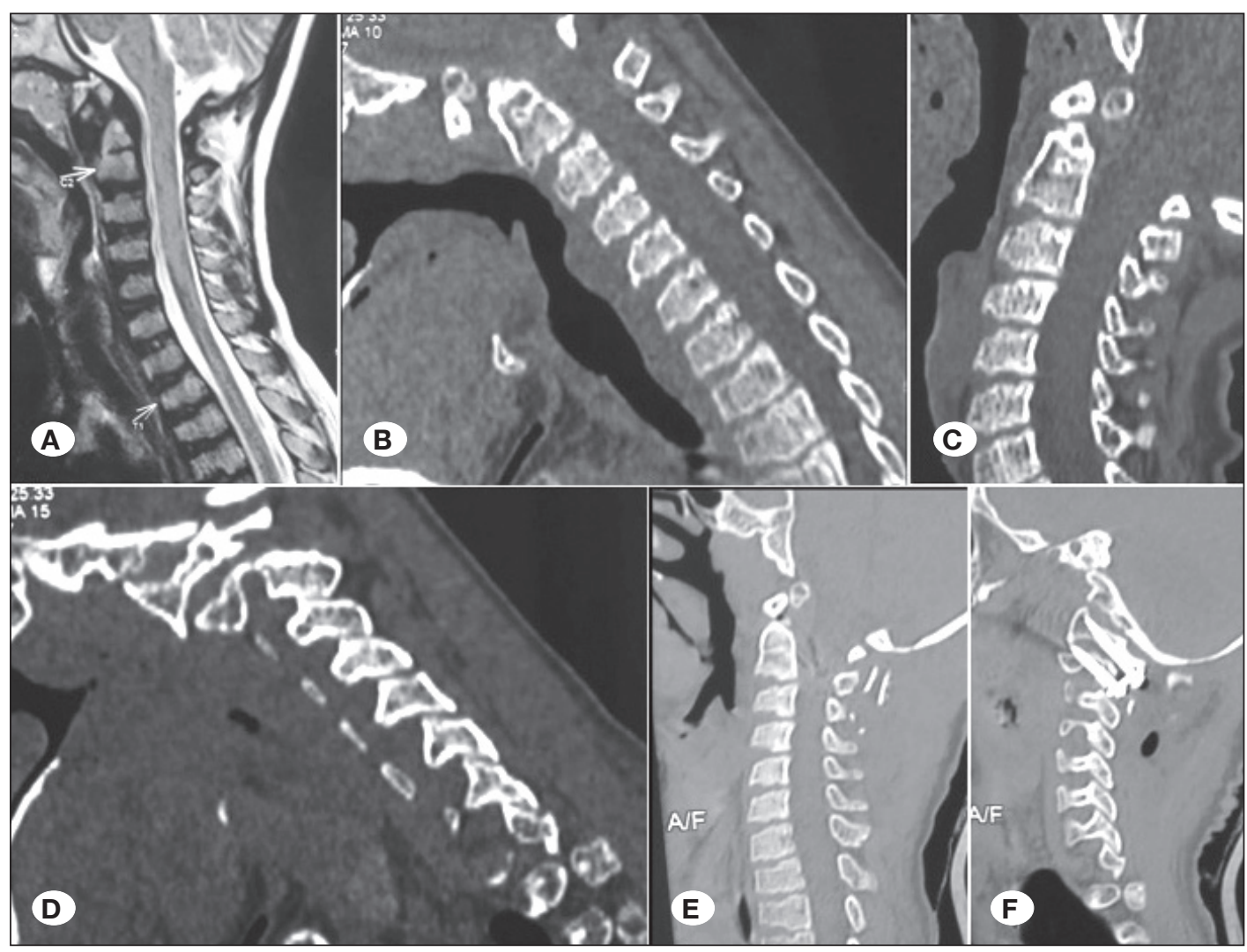

Figure 3: Images of a 14 year old male patient; A) T2 weighted MRI image showing odontoid hypoplasia and atlantoaxial instability. B) Sagittal CT scan with the head in flexion showing the odontoid hypoplasia and atlantoaxial instability. C) Sagittal CT with the head in extension showing reduction of the dislocation.

D) Sagittal cut of CT through the facets showing Type 1 atlantoaxial instability and the high riding vertebral artery.

E) Post-operative sagittal CT scan showing the craniovertebral realignment.

F) Post-operative sagittal CT cut through the facets showing the implant. 

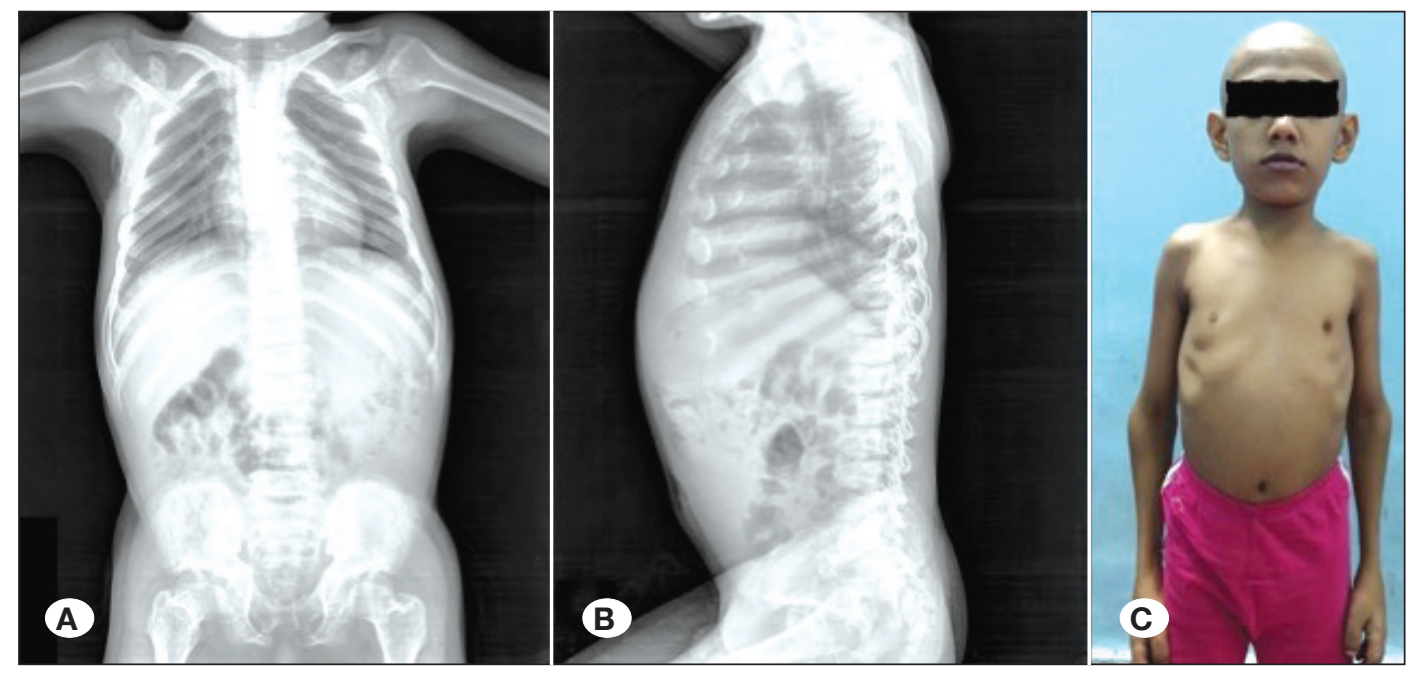

Figure 4: X-ray and clinical photograph of the 14 year old male patient.

A) Antero-posterior radiograph of the chest and abdomen showing the lacy iliac crests and the hypoplastic femoral capital epiphysis.

B) Lateral radiograph of the patient showing the typical double hump appearance of the vertebrae with central beaking and the protuberant abdomen. C) Clinical photograph of the patient.

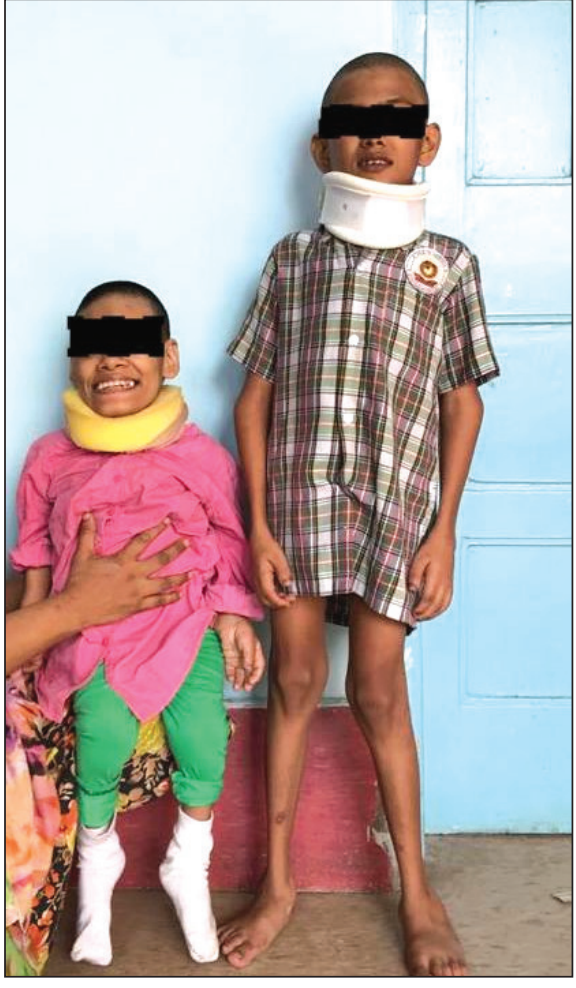

Figure 5:

Post-operative images of the patients after surgery at follow up of 3 months.

\section{REFERENCES}

1. Aglan MS, Temtamy SA, Fateen E, Ashour AM, Eldeeb K, Hosny GA: Dyggve-Melchior-Clausen syndrome: Clinical, genetic, and radiological study of 15 Egyptian patients from nine unrelated families. J Child Orthop 3(6):451-458, 2009

2. Burns C, Powell BR, Hsia YE, Reinker K: Dyggve-MelchiorClausen syndrome: Report of seven patients with the Smith-McCort variant and review of the literature. J Pediatr Orthop 23:88-93, 2003

3. Dyggve HV, Melchior JC, Clausen J: Morquio-Ullrich's disease: An inborn error of metabolism? Arch Dis Child 37:525-534, 1962

4. Girisha KM, Cormier-Daire V, Heuertz S, Phadke RV, Phadke SR: Novel mutation and atlantoaxial dislocation in two siblings from India with Dyggve-Melchior-Clausen syndrome. Eur J Med Genet 51(3):251-256, 2008

5. Goel A: Caudally directed inferior facetal and transfacetal screws for C1-C2 and C1-2-3 fixation. World Neurosurg 100:236-243, 2017

6. Goel A: Goel's classification of atlantoaxial "facetal" dislocation. J Craniovertebr Junction Spine 5(1):3-8, 2014

7. Goel A, Desai K, Muzumdar D: Atlantoaxial fixation using plate and screw method: A report of 160 treated patients. Neurosurgery 51:1351-1357, 2002

8. Goel A, Laheri VK: Plate and screw fixation for atlanto-axial dislocation. (Technical report). Acta Neurochir (Wien) 129:4753, 1994

9. Goel A, Rangnekar R, Shah A, Rai S, Vutha R: Mobilization of the vertebral artery-surgical option for C2 screw fixation in cases with "High Riding" vertebral artery. Oper Neurosurg (Hagerstown) 18(6):648-651, 2020

10. Gupta V, Kohli A, Dewan V: Dyggve melchior clausen syndrome. Indian Pediatr 47(11):973-975, 2010

11. Kandziora F, Neumann L, Schnake KJ, KhodadadyanKlostermann C, Rehart S, Haas NP, Mittlmeier T: Atlantoaxial instability in Dyggve-Melchior-Clausen syndrome. Case report and review of the literature. J Neurosurg 96 Suppl 1:112-117, 2002

12. Khalifa O, Imtiaz F, Al-Sakati N, Al-Manea K, Verloes A, Al-Owain M: Dyggve-Melchior-Clausen syndrome: Novel splice mutation with atlanto-axial subluxation. Eur J Pediatr 170(1):121-126, 2011 